\title{
DA SELETIVIDADE INVISIBILIZADA AO FALSO IGUALITARISMO: O PODER PUNITIVO REPRESENTADO E SIGNIFICADO A PARTIR DA MÍDIA
}

\author{
André Martins Pereira ${ }^{1}$
}

\section{RESUMO}

$\mathrm{O}$ artigo tem por tema a representação e a significação do poder punitivo a partir da mídia. O problema de pesquisa é: em que medida e de que maneira o poder punitivo é representado e significado pela mídia como igualitário? O objetivo é refletir significados e representações do poder punitivo na mídia face à seletividade penal. $\mathrm{O}$ método utilizado é o dedutivo, sendo a técnica de pesquisa a análise da bibliografia sobre o tema a partir da criminologia crítica e da criminologia cultural, concluindo que a cobertura midiática coloca em movimento representações e significados de igualitarismo, encobrindo a seletividade penal.

Palavras-chave: Seletividade - Poder Punitivo - Significado - Mídia - Criminologia Cultural

\section{FROM SELECTIVITY MADE INVISIBLE TO FALSE EGALITARIANISM: THE PUNITIVE POWER REPRESENTED AND SIGNIFIED FROM THE MEDIA}

\begin{abstract}
The article's theme is the representation and meaning of punitive power from the media. The research problem is: to what extent and in what way is punitive power represented and signified by the media as egalitarian? The objective is to reflect meanings and representations of the punitive power in the media in the face of criminal selectivity. The method used is the deductive one, the research technique being the analysis of the bibliography on the subject based on critical criminology and cultural criminology, concluding that media coverage sets in motion representations and meanings of egalitarianism, covering up criminal selectivity.
\end{abstract}

Keywords: Selectivity - Punitive Power - Meaning - Media - Cultural Criminology

\section{INTRODUÇÃO}

$\mathrm{O}$ artigo tem por tema a significação do poder punitivo e do sistema penal como igualitários a partir da mídia que coloca em movimento representações que invisibilizam a seletividade enquanto elemento estruturante do poder punitivo. Levando em conta a seletividade como elemento ou característica inerente ao poder punitivo, estando presente nos processos de criminalização; indagou-se: em que medida e de que maneira o poder punitivo é representado e significado pela mídia como igualitário? A partir do problema que conduz a

\footnotetext{
${ }^{1}$ Mestre em Direitos Humanos pela Universidade Federal do Pará (UFPA). Especialista em Direito Penal e Criminologia pelo Instituto de Política Criminal e Criminologia (ICPC). Membro do Grupo Cabano de Criminologia. Membro do Grupo Direito Penal e Democracia. Defensor Público no Estado do Pará. E-MAIL: andremartinsp@gmail.com
} 
pesquisa, o objetivo é refletir sobre a maneira que a mídia coloca em movimento significados sobre o poder punitivo e correlaciona-los com a seletividade penal. Para tanto, buscou-se refletir, a partir da criminologia crítica sobre a seletividade enquanto elemento estruturante do poder punitivo e definidor de sua crise de legitimidade; sua relação com os processos de criminalização e a dissociação entre realidade material e representações e significados atribuídos ao poder punitivo e ao sistema penal. Posteriormente, buscou-se compreender a relação mídia, crime e controle da criminalidade a partir da criminologia cultural, explorando essencialmente, desde as noções de "loops" e espirais a construção de representações e significados sobre o poder punitivo. Por fim, almejou-se analisar a produção da representação de um poder punitivo igualitário, tomando-se por base a cobertura midiática da Operação Lava Jato, em razão de referido evento representar um marco para o exercício do poder punitivo no Brasil, tornando-o mais agressivo, recrudescendo processos de criminalização e aprofundando a crise de legitimidade no exercício de tal poder, bem como por ter sido um evento massivamente exposto na mídia.

A pesquisa é situada em perspectiva teórica com método dedutivo, sendo a técnica de pesquisa a análise da bibliográfica sobre o tema a partir do referencial teórico centrado essencialmente na criminologia crítica e na criminologia cultural.

A reflexão se justifica diante da intensa exposição midiática do sistema penal após o advento da Operação Lava Jato, que pode ser compreendida como um conjunto de processos de criminalização por falta de cobertura, sabendo-se que uma das formas de produção de significado social, é sua presença nos meios de comunicação, bem como a forma como essa presença se dá. Daí a necessidade de observar atentamente de que forma a cobertura midiática deste evento foi capaz de produzir significados a respeito do poder punitivo e do sistema penal para além do próprio evento em si.

A criminologia enquanto saber, desenvolveu-se de forma a, em um primeiro momento, legitimar o exercício do poder punitivo. Posteriormente, com o avanço das pesquisas a partir da sociologia, com o labeling approach e a incorporação da perspectiva marxista, a criminologia adota viés crítico se propondo a desvelar o real funcionamento do sistema penal, bem como instrumentalizar tensões e rupturas.

No entanto, a abordagem crítica foi capaz de conduzir a teoria criminológica até um determinado ponto, a partir do qual sentiu-se a necessidade de novas abordagens que 
pudessem apreender de forma adequada a complexidade do funcionamento do sistema penal, do crime e de seu controle.

A criminologia cultural se insere nesse contexto de novas abordagens das teorias criminológicas entendidas como pós-críticas e que, partindo dos avanços alcançados pela abordagem crítica, buscam avançar para novas configurações de problemas, novas metodologias e novas formas de entender o crime e seu controle, essencialmente a partir da cultura.

Impossível negar o extenso conhecimento produzido desde a criminologia crítica sobre a relação crime e mídia. Esse conhecimento é essencial para compreender e desvelar os aspectos dessa ralação. No entanto, no mundo contemporâneo, de modernidade tardia, marcado pela profusão midiática, em que todas as pessoas são comunicadores em potencial e dispõe de ferramentas que permitem a criação de informações e a circulação das mesmas de forma quase instantânea e ilimitada; a criminologia cultural oferece novas possibilidades, desde uma abordagem teórica mais afinada com a realidade material atual dos meios de comunicação, até a possibilidade de identificação de novos problemas ou a reconfiguração de problemas já conhecidos, passando por uma profunda reflexão sobre o papel do método e seus impactos na pesquisa em criminologia.

Assim é que se constitui, como referencial teórico adequado para investigar sobre significado e representação do poder punitivo e do sistema penal.

\section{PODER PUNITIVO E SELETIVIDADE PENAL, ENTRE O MATERIAL E O IMATERIAL: A IMPORTÂNCIA DA REPRESENTAÇÃO E DO SIGNIFICADO}

O poder punitivo, aqui entendido como a utilização do direito, dos discursos e instituições jurídicas para classificar condutas como crimes e fazer incidir na realidade material a ameaça e a aplicação da pena de prisão como forma de controle social sobre os corpos e condutas das pessoas, é marcado por traços que podem ser compreendidos como características estruturantes, sendo eles a criminalização de condutas; a seletividade que orienta os processos de criminalização, em todas as suas fases; a fabricação de inimigos que devem ser neutralizados e até mesmo eliminados e a lógica de guerra que mobiliza forças e violências típicas de um contexto bélico.

Portanto, criminalização, seletividade, o inimigo e a lógica de guerra são as marcas de estruturação e exercício do poder punitivo, sendo essencial perceber que tais categorias não podem ser pensadas de forma compartimentada, mesmo em nível teórico, uma vez que 
entender a seletividade pressupõe compreender criminalização, bem como as noções de inimigo e caráter bélico ajudam a compreender a própria seletividade. Na realidade material em que incidem, mais importante ainda é compreender que funcionam de forma conjunta e articulada.

O processo de criminalização envolve desde a escolha de quais condutas serão classificadas como crimes, até quem são as pessoas que devem sofrer a acusação e a punição pela suposta prática de um ato compreendido, definido e significado como crime. De fato, significar, ou seja, produzir o significado, de determinado comportamento como crime, exige as duas etapas. Não basta a primeira com uma definição abstrata do que seria compreendido como crime. É necessária incidência material com a escolha e determinação de pessoas e a afirmação pelo discurso jurídico de uma narrativa que construa de forma concreta a existência do comportamento definido como crime. Assim é que as duas etapas de criminalização se complementam, sendo relevante evitar que as denominações "primárias" e "secundária" criem a impressão de um sentido único como se apenas a criminalização primária estruturasse a criminalização secundária. Trata-se, em verdade, de uma influência mútua quando se pensa em configuração de significado. A criminalização primária constitui a secundaria, abre sua possibilidade de existência, ao mesmo tempo em que a secundária, ao incidir na realidade material, afirma e reforça a criminalização primária.

É no sistema penal, conforme Zaffaroni et al. (2013, p. 60-61), formado por diversas agências, as quais não necessariamente funcionam de forma coordenada, é que se produz e opera a criminalização. A seletividade está presente em ambas as suas fases. Nem todos os comportamentos humanos foram escolhidos e alçados ao patamar de crimes. E dentre aqueles que foram, nem todos os comportamentos que correspondam ao que foi previamente definido como crime são apreendidos pelas agências do sistema penal que operam a criminalização secundária.

Na criminalização primária, para além de uma decisão política, a escolha do que será significado como crime depende do contexto político e social em que ocorre essa escolha. No entanto, de acordo com Zaffaroni et al. (2013, p.44) o programa de criminalização definido na etapa primária, é tão amplo que as agências que funcionam na etapa secundária de criminalização não o conseguem cumprir de forma integral.

De forma geral, a seletividade direciona as forças das agências de criminalização secundária para as pessoas que, em regra, se enquadram nos estereótipos criminais 
(criminalização conforme estereótipo); com menos frequência, para pessoas que não se enquadrem nos estereótipos, mas atuaram com tamanha brutalidade de forma a produzir a vulneração ao sistema penal (criminalização por comportamento grotesco ou trágico); de modo mais excepcional ainda contra alguém que se encontra em posição que o torna praticamente invulnerável ao poder punitivo, mas sofre uma ruptura nessa invulnerabilidade ante a perda de poder hegemônico (criminalização por falta de cobertura). (ZAFFARONI, et al. 2013, p. 49)

Em uma perspectiva teórica, a seletividade se enuncia como elemento estruturante do poder punitivo e do sistema penal. Um dado inerente que está presente sempre que se verifica um processo de criminalização e que vai variar de acordo com o contexto cultural, social e político analisados. E, além de ser um elemento estruturante, é também, conforme Andrade (2012, p. 279), um fator que revela a crise estrutural de legitimidade no exercício do poder punitivo. A forma de operacionalização do poder punitivo, demonstra que o mesmo vive em crise e que tal crise não é de eficiência como o discurso criminológico eficientista costuma alardear, mas sim de legitimidade, sendo a seletividade um elemento que também estrutura essa crise. Em outros termos: a crise se estrutura, dentre ouras razões, porque o poder punitivo é exercido de forma seletiva.

A seletividade se faz sentir de forma evidente na realidade material do poder punitivo, bastando para constatar, a consulta as estatísticas que revelam, por exemplo, o recorte sobre classe e raça dentre as pessoas que estão presas, dados que revelam sem qualquer sombra de dúvida, que o poder punitivo se exerce de forma seletiva.

No entanto, no que concerne à representação e a significação do poder punitivo e do sistema penal, a seletividade permanece oculta, invisibilizada. O sistema penal desenvolve estratégias que cumprem a função de ocultar a seletividade como dado ligado ao poder punitivo. Conforme Zaffaroni et al. (2013, p. 50) a criminalização por falta de cobertura cumpre esse papel de encobrir a seletividade do sistema que se apresenta como igualitário.

Daí ser possível considerar que a seletividade penal é material, porque se faz sentir na realidade de operação do poder punitivo pelo sistema penal e suas agências. Ao mesmo tempo, a representação do poder punitivo quando é estruturada de forma a esconder a seletividade, produz uma imagem imaterial de tal poder, no sentido de sua dissociação para com a realidade. Isso revela a importância da representação e do significado sobre o poder punitivo, uma vez que ao ter um elemento estrutural constitutivo, simultaneamente, de sua 
forma de funcionamento e de sua crise estrutural de legitimidade (seletividade), dissimulado em sua representação, isso produz uma imagem e um significado de um poder punitivo igualitário, dissociado da realidade, portanto.

No entanto, é preciso perceber que a representação que é produzida e o significado forjado sobre o poder penal e as agências do sistema penal como se elas atuassem de forma não seletiva, produz efeitos concretos. $\mathrm{O}$ encobrimento da seletividade e a representação de um poder punitivo igualitário, contribui para que não se percebam os elementos constitutivos de sua crise estrutural de legitimidade. Para além da invisibilização da crise, representações como essa e significados como esse são parte das razões por que os discursos e práticas de descontinuidade para com o poder punitivo, como os minimalismos e os abolicionismos, tenham pouca ou nenhuma ressonância em âmbito de política criminal. Impede-se a percepção e, em verdade, a constituição da crise de legitimidade; e ainda que ela seja percebida, impede-se os tensionamentos e rupturas decorrentes de outros horizontes sobre o poder punitivo.

De toda sorte, a atividade criminalizante, marcada pela seletividade, em ambas as etapas, sofre influxo da empresa moral, a qual se constitui como fenômeno comunicativo. (ZAFFARONI, et al. 2013, p. 45). Isso demonstra a importância de melhor compreender a relação mídia, crime e controle do crime, vez que é nessa relação que as representações e significados sobre poder punitivo e sistema penal são forjados e circulados.

No marco da criminologia crítica, avançou-se bastante na compreensão dessa relação e do papel dos meios de comunicação para o poder punitivo, sendo possível compreender a partir de Zaffaroni et al. (2013, p. 60-61) que os meios de comunicação funcionam como agência do sistema penal, desempenhando papel determinante no exercício do poder punitivo com a estruturação e circulação de significados sobre o mesmo.

De fato, é nos, e por intermédio dos meios de comunicação que significados sobre o poder punitivo são forjados e difundidos; tais quais, crime, criminoso, pena, prisão, dentre diversos outros. Um dos significados, e o que é alvo da presente reflexão, é o de que o poder punitivo se exerce de forma igualitária e que todos estão sujeitos aos mecanismos, estruturas e tecnologias punitivas com a mesma intensidade, o que há muito já se revelou ser falso. No entanto, a não correspondência de um dado com a realidade, não impede que sobre o mesmo sejam forjados representações e significados, os quais ajudam a aumentar essa dissociação entre realidade material e imagem ilusória. 
No mundo de modernidade tardia, em que, diante da profusão irrestritas de novas formas de comunicação, marcadas pela velocidade e ausência de limites geográficos para a circulação de informação, a criminologia cultural abre novas possibilidades e fundamentos para novos horizontes de compreensão sobre representações e significados relacionados ao poder punitivo e ao sistema penal, à relação mídia, crime e seu controle; constituindo-se com uma parte do saber criminológico essencial para a melhor compreensão dessa relação e seus impactos no poder punitivo.

\section{3 "LOOPS" E ESPIRAIS: PENSANDO REPRESENTAÇÕES E SIGNIFICADOS SOBRE PODER PUNITIVO E SISTEMA PENAL.}

Pode-se dizer que a criminologia cultural trata de ver o crime e seu controle a partir do contexto da cultura, a qual, nas relações sociais, seria vista como capaz de produzir o crime e as agências de controle. Explora as variadas formas pelas quais as forças culturais interagem com a prática do crime e o controle do crime nas sociedades modernas. Enfatiza e compreende como centrais as noções de significação, representação e poder na construção do delito. Busca ir além das estreitas noções de crime e justiça criminal para incorporar na análise, demonstrações simbólicas de transgressão e controle, assim como sentimentos e emoções que emergem com e a partir de eventos criminais. Busca integrar na análise também as campanhas públicas e políticas engendradas para definir e delimitar tanto o crime quanto suas consequências. É esse foco mais largo que orienta a criminologia cultural, que busca tanto entender o crime como uma atividade de expressão humana, quanto criticar o saber estabelecido em torno da contemporânea política do crime e do sistema de justiça criminal. (FERRELL, HAYWARD E YOUNG, 2015, p. 03)

Como uma abordagem teórica, metodológica e intervencionista para o estudo do crime, a criminologia cultural coloca a criminalidade e seu controle no contexto da cultura, considerando o crime, as agências e instituições de controle do crime como produtos culturais, ou seja, como construções criativas e por isso devem ser lidos em termos dos significados que carregam. (HAYWARD, 2007, p. 01)

Como alvo de compreensão, a partir da criminologia cultural, então, devem ser incluídos não apenas o delito, o controle social e as agências de controle, como também outros elementos, essencialmente os significados e representações que são produzidos e negociados em torno do poder punitivo e seus diversos elementos. Por isso, de extrema relevância o estudo dos meios de comunicação e seu papel para o poder punitivo. 
Para a criminologia cultural, a representação e a significação do poder punitivo e dos seus elementos se dá de forma circunscrita e relacionada a determinado contexto e/ou momento situado na sociedade em questão.

O significado, então, não é estático ou um dado imutável; está em constante construção, o que ganha relevância quando consideramos o mundo atual como um mundo midiatizado e de espetáculo digital. No mundo contemporâneo em que os meios de comunicação se tornaram abundantes com as infindáveis possibilidades criadas pela tecnologia digital que dissemina imagens; o significado é construído em movimento e de forma coletiva. (FERREL, HAYWARD E YOUNG, 2015, p. 151).

Nesse processo não há uma sequência linear clara acerca dos acontecimentos com a separação perceptível entre o que é real e o que é ficcional, mas, ao contrário, há uma interação inconstante entre o real e o virtual, o que é factual e o que é ficcional. Isso porque a sociedade atual é saturada com significados produzidos de forma coletiva e cheia de incertezas simbólicas, enquanto mensagens midiáticas e traços culturais giram, circulam e vacilam. Por isso, o significado de crime, resistência e controle, permanece sempre instável. (FERREL, HAYWARD E YOUNG, 2015, p. 151e 152)

Então, é de suma importância tentar depreender algumas das formas com as quais o significado do crime circula. Afinal, enquanto a noção de "movimentação cultural" ou de "fluxo", implicam e sugerem instabilidade na construção dos significados coletivos, é desnecessário ressaltar que esse movimento não é, necessariamente, aleatório e que esse fluxo não é irrestrito ou não estruturado. (FERREL, HAYWARD E YOUNG, 2015, p. 154).

É preciso, entender, portanto, que alguns significados e sentidos podem até ser colocados em movimento por algum agente que explore o campo cultural, como jornais, influenciadores digitais, políticos, dentre outros. O essencial é abandonar a ideia de que os significados são forjados unicamente por impulso desses agentes. O processo de estruturação de sentidos é coletivo. O receptor, quando interage com o conteúdo, ajuda a forjar a representação e o seu significado.

A velocidade com que circula a informação no mundo atual é uma marca e uma característica da vida cotidiana que dificilmente pode ser desafiada. No entanto, mais importante do que a velocidade de circulação em si, é a natureza dessa circulação, ou seja, a forma como essa circulação ocorre. Mais importante que a velocidade é a extensão alcançada por imagens mediadas e partes de informações que reverberam e se comprimem sobre si 
mesmas, criando uma porosidade fluida de significados que define a vida na atualidade e a natureza do que se compreende como crime. (FERREL, HAYWARD E YOUNG, 2015, p. 154)

A partir desse ponto de vista, a cultura contemporânea pode ser compreendida como uma serie de "loops", um contínuo processo pelo qual a vida de todo dia recria a si mesma a partir de sua própria imagem. A saturação de situações sociais convertidas em informações e representações sugere que a sequência linear com a qual se habituava construir os significados, está, em sua maioria, perdida; configurando um mundo em que os fantasmas da significação circulam de volta para assombrar e reviver aquilo que eles significam ou constituíram em significado. O que se constitui então é um salão de espelhos mediado, em que as imagens ricocheteiam infinitamente umas nas outras. (FERREL, HAYWARD E YOUNG, 2015, p. 155)

Independente da metáfora, o que fica claro é que há uma fluidez cultural circulando que desafia qualquer distinção precisa entre um evento e sua representação, entre uma imagem mediada e seus efeitos, entre um momento de um crime e sua constante construção por meio de significados erigidos de forma coletiva. Com isso é possível sugerir que no mundo pós-moderno, a arenosa realidade do dia a dia do crime, da violência e da justiça criminal; é perigosamente confundido com a sua própria representação. (FERREL, HAYWARD E YOUNG, 2015, p. 155)

Nesse sentido, se esse processo constitui um ponto de partida para compreender a constituição contemporânea de significados; também marca um ponto de partida para a criminologia cultural, uma vez que a natureza mediada da cultura contemporânea não apenas constitui o significado de crime e criminalidade, como também circula de volta para amplificar, distorcer e definir a experiência do crime e da criminalidade ela própria. (FERREL, HAYWARD E YOUNG, 2015, p. 155)

No entanto, a noção de "loops", embora, certamente, capture alguma coisa da fluidez reflexiva da cultura contemporânea, algumas vezes oferece apenas alguns quadros de um filme mais longo. E nesse ponto a noção de espirais se torna relevante, vez que o significado coletivo de crime e desvio não é feito apenas uma vez, mas repetidas vezes, como parte de uma espiral amplificadora que se enrola em avanço e retrocesso através dos meios de comunicação e da percepção do público. Assim, um "loop" de significado, nunca realmente retorna ao ponto de partida; ao contrário; se move para adiante e distante para novas 
experiências e novas percepções, ecoando por todo o tempo ou, em outras ocasiões, minando significados e experiências já construídos. (FERREL, HAYWARD E YOUNG, 2015, p. 158)

As noções de "loops" e espirais implicam, talvez, uma certa suavidade de movimento, uma trajetória macia enquanto os significados de crime e justiça criminal circulam através da cultura popular. Mas as trajetórias podem mudar. Movimentos espirais de significado podem ser feitos para alterar o curso e servir a novos interesses e mestres políticos. Por exemplo, após os atentados do 2001 no World Trade Center, o espiral da guerra contra as drogas ganha nova direção, vez que os guardiães da guerra às drogas, para a manutenção da mesma, construíram uma confluência cultural entre drogas e terrorismo por meio da associação o uso recreativo de drogas com a ocorrência de atos de terrorismo. (FERREL, HAYWARD E YOUNG, 2015, p. 160).

Então, a partir dos esforços para a desnaturalização dos acontecimentos da vida cotidiana, é possível compreender que; sobre crime, controle do crime, poder punitivo e sistema penal constroem-se, de forma coletiva representações e significados. O que realmente é poder punitivo e como funciona o sistema penal e suas agências, está permanente confundido com suas representações e seus significados.

A variedade e a capacidade de alcance dos meios de comunicação na atualidade propiciam a circulação de imagens e informações que levam à construção coletiva do significado sobre um determinado evento. Tal significado não será construído somente por parte daqueles que estão envolvidos diretamente nos eventos, mas por todos aqueles que entram em contato com a informação divulgada e a reproduzem, seja nos veículos oficiais de comunicação, seja nos veículos informais ou mesmo na comunicação que se dá no dia a dia entre pessoas em uma simples conversa, troca de mensagens em aplicativos de mensagens, troca de likes, comentários e compartilhamento de imagens e postagens em redes sociais. Todas essas interações são capazes de produzir o significado de determinado evento e por isso se dizer que o significado é produzido de forma coletiva. Além disso, a velocidade de circulação das informações é imensa e irrestrita no mundo marcado pela tecnologia capaz de romper qualquer barreira espacial ou temporal.

Porém mais relevante para a percepção crítica sobre a construção de significados, não é a mera velocidade de circulação, mas a forma de tal circulação que pode se dar em forma de “loops" e espirais, de forma que o mundo se forje em termos de significado sobre sua própria 
imagem em um processo que dilui a barreira entre o real e o ficcional, entre um evento e sua representação, forjando significados a partir dessa dissociação.

Nesse sentido, a criminologia cultural possui grande potencial para promover a ruptura sobre visões mais tradicionais da relação entre mídia e crime, superando, por exemplo, a simplificação de que há uma simples manipulação de representações e significados de eventos sociais pela mídia hegemônica ou de que os meios de comunicação é que produzem efeitos nas relações sociais. Com a criminologia cultural, é possível compreender que os significados são forjados de forma coletiva e que, portanto, não é apenas a mídia que produz efeitos na audiência e nas relações sociais, mas que também há um efeito da audiência e das relações sociais sobre os meios de comunicação. Os desejos da audiência e a conjuntura social, econômica e política são capazes, por exemplo, de alterar a agenda da mídia e pautar o que ganha proeminência para divulgação, constituindo novas representações e novos significados, reforçando significados já solidificados ou mesmo minando e alterando o sentido de significados.

A representação e, portanto, os significados do poder punitivo e do sistema penal e suas agências demonstram grande relevância, exatamente porque estão sujeitos à essa dinâmica fluída, vez que são construídos de forma coletiva e em movimento por intermédio dos meios de comunicação, e que também estão sujeitos a diversas influências conjunturais, econômicas e políticas.

4 A COBERTURA MIDIÁtiCA DA OPERAÇÃO LAVA JATO E A REPRESENTAÇÃO E A SIGNIFICAÇÃO DO PODER PUNITIVO COMO IGUALITÁRIO PELA OCULTAÇÃO DA SELETIVIDADE.

A larga exposição midiática da Operação Lava Jato faz com que a mesma seja um excelente lugar a partir do qual se pode pensar sobre representações e significados acerca do poder punitivo e do sistema penal. Não apenas isso, mas sobretudo pelo fato de referida operação constituir um marco na história do poder punitivo nacional, constituindo-se em evento revestido da capacidade de aprofundar a sua crise estrutural de legitimidade.

A partir da mencionada operação o exercício do poder punitivo torna-se mais recrudescido com o desencadeamento de práticas violadoras de direitos e garantias fundamentais, inclusive, chanceladas pelos tribunais superiores. Em termos de política criminal, desencadeia um movimento de endurecimento no poder punitivo em esfera legislativa. Os já existentes movimentos inspirados na "lei e ordem" e no desprezo pela vida e 
dignidade das pessoas acusadas e presas, ganha força e intensidade. Isso provoca uma diminuição do espaço que já era pequeno para a ressonância de discursos e práticas de descontinuidade para com a forma atual de exercício do poder punitivo (como os minimalismos e os abolicionismos), levando a uma lógica de relegitimação pela aposta de que o sistema penal se tornará mais eficiente se a política criminal for mais dura com o que é interpretado como crime. (PEREIRA, 2020, p. 170)

Em termos de representação e significado para o poder punitivo, a Operação Lava Jato cumpre papel de elevada importância. Sua cobertura midiática ao constituir representações e significados sobre a própria operação e os envolvidos, alcança o poder punitivo de modo a fazer parecer que o que se expõe acerca da operação é a maneira pela qual funciona o sistema penal e suas agências de forma geral. Cria-se, assim, uma representação, não apenas da operação, mas do poder punitivo e das agências do sistema penal. A partir desta representação, estruturam-se significados que impactam o poder punitivo em si, reforçando a maneira como o mesmo se dá e aprofundando suas características que enunciam sua própria crise estrutural de legitimidade, em especial a seletividade.

A seletividade é uma característica do exercício do poder punitivo e do funcionamento do sistema penal que é essencial á própria manutenção do poder punitivo tal qual estruturado. No entanto, ela é invisibilizada pelas mais diversas estratégias, incluindo-se aqui a funcionamento da mídia e dos meios de comunicação em geral que reforçam a crença de que o sistema penal funciona de forma igualitária.

Dessa forma a mídia tende a expor com preponderância delitos cometidos pela parcela da população subalternizada, que resta em situação de desvantagem social e econômica, e, portanto, em maior risco de criminalização; enquanto esconde os delitos cometidos pelos membros dos extratos hegemônicos da sociedade. Essa foi a forma mais usual de retratação do poder punitivo e do sistema penal pelos meios de comunicação até o advento da Operação Lava Jato. Não que esta forma de exposição tenha cessado após o início da referida operação e sua larga exposição midiática, mas a representação do funcionamento do sistema penal e do poder punitivo ganharam novos contornos.

Após o início da Operação Lava Jato, houve uma massiva exposição de fatos compreendidos como crimes praticados por políticos e ricos empresários, que forma expostos sendo presos, algemados, processados e em salas de audiência sendo interrogados por juízes e membros do ministério público retratados como paladinos da justiça e da moralidade, criando 
a representação de um poder punitivo exercido de forma igualitária, demonstrando que as agências do sistema penal funcionam de maneira a alcançar todas as pessoas que cometam fatos interpretados como crimes independentemente de sua força política e/ou econômica.

Porém, um olhar mais atento, revela que a excessiva exposição midiática da Operação Lava Jato, não elimina a seletividade, apenas a escamoteia na representação que é feita sobre referida operação e no significado que se negocia sobre o poder punitivo.

Interessante notar também que a própria operacionalização da Lava Jato é impregnada de seletividade - embora sua representação obscureça isso - no sentido de que os atos praticados em seu bojo diferem da maneira como, os atos em geral para os outros casos em curso nas agências do sistema penal, são conduzidos.

O volume de meios e recursos empregados pela Operação Lava Jato nas
investigações policiais e, em especial, no cumprimento de decisões judiciais
(ordens de prisão provisória e de busca e apreensão) revela exatamente o
inverso aos olhos do bom observador. Os escolhidos de todo dia do sistema
penal não são transportados em comboios de veículos da polícia. Quem vive
a rotina da justiça criminal sabe das dificuldades burocráticas, muitas vezes
insuperáveis, para se realizar a transferência de réus presos entre cidades,
sobretudo se isso depender de transporte aéreo. Mandados de prisão
acumulam-se nas delegacias de polícia, aguardando cumprimento por
semanas, meses e até anos. Provas técnicas deixam de ser produzidas porque
não há peritos nos serviços de criminalística. Assim, a celeridade e eficácia
das diligências da Operação Lava Jato, diversamente do que faz acreditar a
cobertura midiática, intensifica a seletividade do sistema penal e desnuda seu
caráter discriminatório. Para o controle penal, há réus e Réus (com R
maiúsculo). Se é correto dizer que o poder punitivo sempre tratou
determinadas pessoas como inimigos, não será menos acertado afirmar que a
Operação Lava Jato elegeu não um outro inimigo, mas um inimigo a mais,
só que momentâneo, temporário, e instrumentalizou-o como um bode
expiatório. Nada pode ser mais falacioso do que a elitização da resposta
penal. (GOMES, 2016, p. 233 a 240)

Se antes, os delitos dessa parcela da população (parlamentares e ricos empresários) pertencente a parcela hegemônica da sociedade eram ignorados pela mídia, agora não são mais. A exposição massiva de delitos cometidos por empresários e políticos no âmbito da Operação Lava Jato é, antes de tudo, seletiva, e também ocorre por fins mercadológicos para angariar dividendos econômicos aos veículos de comunicação com o aumento da audiência, em verdadeiro processo de mercantilização do crime. $\mathrm{O}$ fator econômico está presente e não deve ser ignorado enquanto fator que direciona e condiciona a seleção de fatos a serem expostos e o enquadramento, a forma como serão expostos. E na busca por vantagem 
econômica, os meios de comunicação colocam em movimento representações e significados que relegitimam o poder punitivo.

Se, por muito tempo, foi construída coletivamente, e com a participação dos meios de comunicação, o significado de que as classes mais pobres e mais vulneráveis social e economicamente são as mais propensas ao cometimento de delito, o que fez com que se estabelecesse no senso comum o padrão de percepção do positivismo criminológico, que molda a crença de existir crime apenas em determinada parcela da população; após o surgimento da Operação Lava Jato e sua cobertura midiática, passou-se a expor que o delito também existe entre ricos empresários e políticos.

Então, se durante muito tempo, a exposição midiática reforçava uma imagem já construída e, por consequência, um significado também já construído, uma imagem que ricocheteia em si mesma em um tipo de "loop", com a cobertura midiática da Operação Lava Jato, é possível perceber que esse significado toma um novo rumo em sua constituição a partir da inclusão de novos elementos. Algo se altera em relação a representação do sistema penal e ao significado da seletividade quando a mídia passa a expor não só a existência de criminalidade nos altos extratos sociais, mas a atuação do judiciário e da polícia para processar e punir as pessoas que supostamente cometeram tais delitos, sendo possível compreender esses novos elementos como uma reconfiguração do "loop" por meio de espirais, uma imagem e representação que se dobra sobre si mesma, mas não volta ao mesmo lugar de onde partiu, estruturando novos significados.

Essa alteração na exposição midiática incide de forma a produzir ou reforçar o significado e a representação que é feita e construída sobre o poder punitivo e o sistema penal. Partindo da existência de distinção entre evento social e sua representação e seu significado, pode-se dizer que a Operação Lava Jato em si, não é ou não foi capaz de alterar a realidade do funcionamento do sistema de justiça criminal no país no que diz respeito à seletividade. Este não deixou de ser seletivo e passou a ser igualitário. Ao contrário, mantem-se seletivo; uma seletividade que opera com marcadores de classe e raça; e dentro da classe mais alta também, na medida em que nem todos os ditos atos de corrupção do empresariado e dos políticos nacionais são capturados nas redes das agências policiais e judiciais do sistema penal, a depender da cobertura contra a criminalização que tais personagens ostentem em determinado contexto. 
O que se altera então, a partir da cobertura midiática da Operação Lava Jato é a representação e, por consequência, o significado construído coletivamente sobre o funcionamento do sistema penal e do poder punitivo, que ganha contornos de igualitarismo. É de suma relevância admitir que o que se produz é uma modificação na representação mais usualmente apresentada, mas isso não quer dizer que não produza efeitos no mundo material. Essa nova forma de representação e esse novo significado conferem a possibilidade de que as coisas continuem do mesmo jeito e nada seja mudado. Cumprem um papel de estabilização da crise do poder punitivo, evitando que a mesma seja percebida, produzindo a impressão de que as agências do sistema, principalmente, o Poder Judiciário, finalmente estão funcionando como deveriam; rumo ao ajuste de eficiência que faltava. Outro efeito, é forjar a condição de possibilidade para que o poder punitivo seja exercido de forma recrudescida, com o aprofundamento dos processos de criminalização, ou seja, o agravamento de sua crise de legitimidade.

Assim, foi possível observar que a cobertura midiática da Operação Lava Jato dilui a fronteira entre o real e o ficcional, provocando, por meio de "loops" e espirais, efeitos na construção de representações e significados sobre o sistema penal e sobre o poder punitivo que passa a ter uma aura de igualitarismo. A seletividade, embora presente, é escamoteada como estratégia para estruturar um determinado sentido de poder punitivo dissociado da realidade; o igualitário.

\section{CONSIDERAÇÕES FINAIS}

Representação e significado abrem possibilidades importantes para a compreensão do poder punitivo e do funcionamento das agências do sistema penal. A criminologia cultural permite esse alargamento de horizontes, vez que sustenta uma abordagem teórica, metodológica e intervencionista para a compreensão do crime, da reação a ele e das agências do sistema penal, buscando compreender os elementos envolvidos no complexo fenômeno do crime, a partir da cultura.

Afinal, o crime; o que é interpretado como tal; as diversas maneiras de reagir a ele e toda a estrutura envolvida nessa reação, são produtos culturais, no sentido de que são forjados a partir dos diversos e variados contextos culturais. A abordagem dessa criminologia, envida claros esforços para desnaturalizar os acontecimentos sociais interpretados como delitos. Esses eventos passam a ser compreendidos como construções coletivas e por isso, a os significados que carregam ganha extrema relevância. Isso significa que as representações e 
significados que são produzidos e negociados entorno do poder punitivo e seus diversos elementos devem ser alvo de inquietação, investigação e intervenção.

Pensar em representações e significados, perpassa pela relação entre mídia e poder punitivo. Isso porque os meios de comunicação cumprem papel determinante na construção de representações e significados. Nesse aspecto a criminologia cultural abre diversas possibilidades de analisar a relação entre a mídia, o crime e o controle da criminalidade de forma mais profunda e para além das implicações materialistas, de forma a ser possível incluir fatores como emoções e percepções, significado das imagens e do discurso na sociedade atual e de que forma tais elementos impactam na questão criminal, no funcionamento do sistema penal e na política criminal.

No que se refere à relação entre mídia e sistema penal, se em um primeiro momento se compreendia que a mídia manipulava informações, imagens e discursos para fabricar consenso em torno de uma ideia, agora é possível perceber que a construção do significado de um objeto ou evento social é bem mais complexa e se dá de forma coletiva e em movimento. Passou-se a perceber que o efeito não se dá apenas no sentido dos meios de comunicação para audiência, mas também ocorre no sentido oposto, audiência para os meios de comunicação, uma vez que os desejos da audiência podem pautar a agenda dos meios de comunicação por questões mercadológicas. A relação em verdade é mútua, constante, permanente e fluída. Múltiplas influências em várias direções. Se a ideia de movimento é usada como metáfora, pode-se dizer que é mais de natureza circular e espiralar do que linear.

Além disso, as interferências e relações se dão também a partir das necessidades criadas em decorrência das relações de poder. Assim, a depender do momento político e das tensões de força estabelecidas, a cobertura midiática sobre determinado evento poderá assumir as mais variadas formas e assim impactar em representações e significados.

Em qualquer caso, o contato com essa informação produzida a partir dos meios de comunicação sobre determinado evento e a interação com ela nas relações sociais do dia a dia de forma pessoal ou mediada, constrói também o significado de forma coletiva. Assim, chegase à percepção da separação entre um evento e sua representação e consequentemente seu significado. E é nessa produção de significado a partir da dissociação entre o real e o representado que se pode buscar entender em que medida e de que maneira o poder punitivo é representado e significado como igualitário nos processos de criminalização. 
A denominada Operação Lava Jato, como um evento que produziu grande impacto no poder punitivo nacional, agravando sua crise de legitimidade, é um bom lugar a partir do qual se pode pensar nessa representação e nessa significação com contornos de igualitarismo. Pode-se dizer que os processos de criminalização objetos da mencionada operação são processo de criminalização por falta de cobertura e como tais, se constituem também como empresas morais, cumprindo o papel de reforçar a crença ilusória de que o poder punitivo é exercido pelas agências do sistema penal de forma igualitária, escamoteando a seletividade.

Utilizando a noção de "loops" e espirais foi possível perceber que essa ilusão em relação à seletividade se produz por intermédio da cobertura midiática da Operação Lava Jato, a qual reforça a diluição entre o real e o ficcional. Essa intensa exposição midiática desempenha papel relevante na representação e na produção de significados em relação ao sistema penal que ganha uma aura de igualitarismo e justiça por meio da exposição excessiva de prisões e punições de parlamentares e ricos empresários envolvidos em casos de corrupção. Produz-se, assim, o significado de que o sistema penal e o poder punitivo funcionam de forma igualitária, que todas as pessoas estão sujeitas as suas forças na mesma intensidade, ou seja, que todos possuem o mesmo risco de criminalização, o que já se revelou falso há muito tempo.

O efeito disso, é o encobrimento, a invisibilização da seletividade na representação que é feita do poder punitivo e no significado que sobre o mesmo é construído; embora a realidade material do o sistema penal e suas agências continue a ser marcada pela seletividade e embora a seletividade seja, ao mesmo tempo, elemento constitutivo do poder punitivo e uma das identidades de sua crise de legitimidade.

Ao contrário do que propala o discurso eficientista hegemônico a crise do sistema penal é de legitimidade e não de eficiência. O exercício do poder punitivo é ilegítimo, dentre vários fatores, também porque se dá de forma seletiva a partir de marcadores de raça, classe e gênero, o que faz com que parte da população detenha consigo um risco criminalizante maior, revelando maior vulnerabilidade às forças das agências do sistema penal.

Esse encobrimento da seletividade, impede que ela seja identificada na representação e na significação do poder punitivo como elemento constitutivo e como fator de crise, o que obsta a constituição da crise em sua dimensão de legitimidade e mantém a aparência de que a crise é de eficiência. Constitui elemento de relegitimação no sentido de fazer parecer que, agora, as agências do sistema penal estão funcionando como sempre deveriam ter funcionado, 
como sempre se esperou que funcionassem a partir da lógica de que a reação ao crime deve ser dura. Nesse aspecto, isso cria condições comunicacionais para que se fortaleça a representação e o significado de que a crise de eficiência está sendo enfrentada com sucesso, deixando escondido que a verdadeira crise é de legitimidade.

Ao fim, na realidade material, o poder punitivo continua sendo exercido de forma seletiva e discriminatória pelas agências do sistema penal, porém a representação e a significação sobre eles colocada em movimento pelos meios de comunicação, impacta a realidade material, demonstrando a importância desses elementos mais fluídos como sentimentos, representações e significados na compreensão do poder punitivo.

\section{REFERÊENCIAS:}

ANDRADE, Vera Regina Pereira de. Pelas Mãos da Criminologia: O controle penal para além da (des)ilusão. Rio de Janeiro: Revan, 2012.

BARATTA, Alessandro. Criminologia Crítica e Crítica do Direito Penal: Introdução à Sociologia do Direito Penal. $3^{\mathrm{a}}$ ed. Trad. Juarez Cirino dos Santos. Rio de Janeiro: Revan, 2002.

BUDÓ, Marília de Nardin. Mídia e controle social: da construção da criminalidade dos movimentos sociais à reprodução da violência estrutural. Rio de Janeiro: Revan, 2013.

CARVALHO, Salo de. Das subculturas desviantes ao tribalismo urbano (itinerários da criminologia cultural através do movimento punk). In: LINCK, José Antônio. [et al]. Criminologia cultural e rock. Rio de Janeiro: Lumen Juris, 2011.

CARVALHO, Salo de. Criminologia Cultural, complexidade e as fronteiras de pesquisa nas ciências criminais. Revista Brasileira de Ciências Criminais, v. 17, n. 81, p. 294-338, nov/dez. 2009.

FERREL, Jeff. Crime and Culture. In HALE, Chris, et all. Criminology. London / New York: Oxford University Press, 2007.

FERREL, Jeff. Kill Method: A Provocation. Journal of Theoretical and Philosophical Criminology, vol 1 (1), 2009.

FERRELL, Jeff. Definition of Cultural Criminology in the Blackwell Encyclopedia of Sociology. $2011 . \quad$ Disponível em: 
http://blogs.kent.ac.uk/culturalcriminology/files/2011/03/cult-crim-blackwell-encysoc.pdf. Acesso em 13 de maio de 2017.

FERRELL, Jeff. HAYWARD, Keith. YOUNG, Jock. Cultural Criminology. London. Sage, 2015.

GOMES, Marcus Alan de Melo. Crítica à Cobertura Midiática da Operação Lava Jato. Revista Brasileira de Ciências Criminais, v. 122, agosto, 2016.

GOMES, Marcus Alan de Melo. Mídia e Sistema Penal: As distorções da criminalização nos meios de comunicação. Rio de Janeiro: Revan, 2015.

HAYWARD, Keith. Definition of Cultural Criminology in the Dictionary of Youth Justice. 2007. Disponível em https://blogs.kent.ac.uk/culturalcriminology/files/2011/03/youth-justicedictionary.pdf. Acesso em 13 de maio de 2017.

JEWKES, Yvonne. Media and crime. $2^{\mathrm{a}}$ ed. Londres: Sage, 2004.

PEREIRA, André Martins. Populismo Penal e Política Criminal Brasileira. São Paulo: Tirant lo Blanch, 2020.

ZAFFARONI, Eugenio Raul et al. Direito Penal Brasileiro. Rio de Janeiro: Revan, 2013, v.1.

ZAFFARONI, Eugenio Raúl. Em busca das penas perdidas: a perda de legitimidade do sistema penal. Rio de Janeiro: Revan, 2001.

ZAFFARONI, Eugenio Raúl. O inimigo no direito penal. Rio de Janeiro: Revan, 2011. (Coleção Pensamento Criminológico, n. 14). 